DOI: 10.20472/IAC.2018.039.026

MICHAEL LAUBSCHER

North-West University , South Africa, South Africa

\title{
CONFIDENTIALITY IN MEDIATION - WHAT CAN WE LEARN ?
}

\begin{abstract}
:
Confidentiality is one of the cornerstones of mediation, but it is also one of the great areas of uncertainty of mediation. Although the necessity for confidentiality in mediation is obvious, the application of this vital element of mediation often leads to disparate and sometimes, unwanted, results. Despite advanced legislation and an ever-increasing body of case law, the application of mediation confidentiality still remains as issue. In a country like South Africa where mediation is still , in many ways, in its infancy, it might be prudent to consider the manner and way in which other countries (which have more experience in dealing with this issue) have dealt with mediation confidentiality. The insight that can be gained from doing this, will stand mediation in South Africa in good stead.
\end{abstract}

\section{Keywords:}

confidentiality, mediation, South Africa, uncertainty, application, legislation, common law jen abstrakt do proceedings. $\mathrm{k}$. 